Check for updates

The BMJ

Cite this as: BMJ 2021;373:n1483 http://dx.doi.org/10.1136/bmj.n1483 Published: 09 June 2021

\section{Covid-19: Tests must be more rigorously regulated to protect public, say statisticians}

\author{
Gareth lacobucci
}

Statistical experts have called for new standards for diagnostic tests in response to regulatory gaps identified during the covid-19 pandemic.

Current legislation does not require tests to be evaluated in the settings where they will be used. But in a review of the statistical evidence needed to assure the performance of new tests, ${ }^{1}$ the Royal Statistical Society (RSS) has called on the Medicines and Healthcare Products Regulatory Agency to "review and revise the national licensing process for in vitro diagnostics to ensure public safety is protected."

The RSS's Working Group on Diagnostic Tests, which produced the review, said that action was needed because tests such as the rapid Innova lateral flow test had come to market during the pandemic without evidence of their accuracy for many of their subsequent uses and had been marketed using claims that were not supported by strong studies.

Initial claims about the rapid tests' sensitivity were based on evaluations done in laboratory settings in patients with symptoms, but the tests are now being used for self-testing of asymptomatic people at home, in schools, and in other settings, the RSS noted.

The working group also emphasised that regulatory assessment of a test's safety should go beyond just the safety of the device itself and should include the potentially harmful consequences of false negatives and false positives. It highlighted that the usefulness of a test decreases as a disease becomes rarer, increasing the chances of false positive results.

\section{Real world settings}

The review also called for more transparency around testing. It said that the people providing tests to patients and the public have a responsibility to ensure that an informed choice can be made and that people are aware of the advantages and disadvantages of testing.

It argued that during the pandemic there has not been enough explanation to the public on the use of lateral flow tests and the fact that negative test results do not rule out infection. "It is essential that the public are aware of this, as misinterpretation of a negative test result as indicating an individual is safe and does not have the infection could lead to disinhibition, greater risk taking, and hence increased transmission." it said.

Deborah Ashby, co-chair of the RSS Working Group on Diagnostic Tests, said, "Testing has been a key focus of many government's strategies in fighting covid, but the lack of statistical standards has caused issues, with tests coming to market without enough known on their effectiveness. We urge regulators to take on board our recommendations, to allow for more scrutiny of diagnostics more generally and for future pandemics.”

Jon Deeks, also co-chair of the working group, said, "While no one questions the need for an evidence based approach to vaccines and treatments, the proper assessment of the suitability of covid-19 tests has been neglected.

"Investment in well designed studies evaluating tests in the real world settings where they are used must become standard practice. We must learn from the mistakes made during the pandemic and put in place requirements for stronger science, better regulation, and more transparency."

Royal Statistical Society. Diagnostic Tests Working Group report. Jun 2021 https://rss.org.uk/RSS/media/File-library/Policy/2021/RSS-Diagnostic-testsreport-FINAL.pdf.

This article is made freely available for use in accordance with BMJ's website terms and conditions for the duration of the covid-19 pandemic or until otherwise determined by BMJ. You may use, download and print the article for any lawful, non-commercial purpose (including text and data mining) provided that all copyright notices and trade marks are retained. 